\title{
Multiobjective Optimization for Forming Process Parameters of Ultrahigh Strength Steel BR1500HS
}

\author{
Xin Shang, ${ }^{1}$ Lijuan Pang $\mathbb{D}^{2}{ }^{2}$ and Sheng-Gui Chen ${ }^{1}$ \\ ${ }^{1}$ College of Mechanical Engineering, Dongguan University of Technology, Dongguan 523000, China \\ ${ }^{2}$ College of Vanadium and Titanium, Panzhihua University, Panzhihua 617000, China \\ Correspondence should be addressed to Lijuan Pang; 26733982@qq.com
}

Received 2 July 2020; Revised 11 May 2021; Accepted 20 June 2021; Published 13 August 2021

Academic Editor: José António Fonseca de Oliveira Correia

Copyright (c) 2021 Xin Shang et al. This is an open access article distributed under the Creative Commons Attribution License, which permits unrestricted use, distribution, and reproduction in any medium, provided the original work is properly cited.

This paper focuses on obtaining the optimum process parameters and improving the mechanical properties of ultrahigh strength steel BR1500S. Many experimental data are obtained, and then response surface methodology (RSM) is used to obtain the optimum parameters. Combining the experimental data with RSM, some conclusions are summarized. When the cooling rate reaches $30^{\circ} \mathrm{C} / \mathrm{s}$, martensite content in microstructure reaches up to $95 \%$. The optimum regions of quenching hardness, tensile strength, and elongation are obtained when the temperature is about $900^{\circ} \mathrm{C}$, and the holding time is about $0 \sim 4 \mathrm{~min}$. Results of multiobjective optimizations show that global optimal value is gained at $906.5^{\circ} \mathrm{C}$, and the holding time is 0 min. Predicted optimum values of quenching hardness, tensile strength, and elongation are not less than $51.03 \mathrm{HRC}, 1,671 \mathrm{MPa}$, and $8.75 \%$, respectively. The application of RSM is notably successful in predicting the process parameters of hot forming.

\section{Introduction}

Ultrahigh strength steel (UHSS) can form thin parts to meet the requirements for automobile components because of its higher strength, lighter weight, lower fuel consumption, and higher security. If the usage of UHSS in auto body reaches up to $80 \%$, the total weight of auto body decreases by $20 \%$ on the premise of the same cost [1]. Thus, the UHSS and its hot forming technology hold wide prospects in the automobile industry, especially for some critical crash components such as A-pillars, B-pillars, and side rails [2-4]. During the hot stamping process of UHSS, the blank is initially austenitization. Hot stamping is a thermal coupling process. In this process, many parameters must be considered, such as properties of deformed materials, quenching time, heating temperature, holding time, and cooling rate [5-7]. These parameters are very crucial to the eventual mechanical properties for deformed UHSS [8-10]. So, many researchers have struggled to investigate the technological parameters of the hot stamping process in order to attain the best strategies for the hot stamping process. Turetta has studied the hot deforming process of $1.5 \mathrm{~mm}$ thick $22 \mathrm{MnB} 5$ steel and drawn a conclusion. The minimum cooling rate to avoid the appearance of bainite is $30^{\circ} \mathrm{C} / \mathrm{s}$, and the martensitic transformation temperature (Ms) for this steel is $382^{\circ} \mathrm{C}$ [11]. But the martensitic transformation rate of this steel has not been investigated in his paper, even though this is very important to the form and homogeneity of martensite during the hot stamping process. Naderi et al. have studied the martensitic transformation temperature and holding time to get the conclusion that the maximum content of martensite can be obtained at $950^{\circ} \mathrm{C}$ holding for 3 minutes $[12,13]$. In this study, the author has also proposed that the forming of austenite directly affects the martensite transformation. But the effect of bainite in the final microstructure on the quality of formed parts has not been analyzed deeply. Some scholars have done some researches about the influence of cooling rate on the characteristic of the martensite transformation under high strain rates. It has been pointed out that the hot stamping process would be affected by an excessive strain rate. Unfortunately, the study has not been proceeded deeply $[3,5,14-16]$. Nikravesh has selected four boron-free alloy steels as the experimental subjects to conduct the hot stamping experiment with refrigerating media water and 
liquid nitrogen. It has turned out that with liquid nitrogen, the steel has superior strength and wholly martensite microstructure. However, with water as cooling media, the steel shows better formability but lower strength because there is ferrite in the final microstructure, but not much [17]. As known, it is hard to industrialize to select liquid nitrogen as refrigerating media. Nikravesh et al. have studied the effect of hot plastic deformation and cooling rate on Ms and austenite transformation temperature of $22 \mathrm{MnB} 5$ steel. It has been found out that lowering the cooling rate can elevate the Ms point and also descend Mf point, while hot plastic deformation can hinder martensitic transformation resulting in lower Ms and Mf. But this analysis is not qualitative [18-20].

All the above studies have one common point that the interaction effects of these three parameters (cooling rate, austenite transformation temperature, and holding time) have not been taken into account. Considering this, in this paper in order to reduce the blindness of repeated experiments and get the best quenching process parameters, BR1500HS has been selected as the experimental subject, and the effect of cooling rate on the mechanical properties of BR1500HS is studied to obtain an appropriate cooling rate range firstly. Next, the effects of austenite temperature and holding time on quenching hardness, tensile strength, and elongation of BR1500HS are optimized with response surface methodology based on the results of cooling rate. The optimum value of each single-objective model is firstly obtained by using the response surface models. Then, RSM Method is chosen to find the global optimum value of this multiobjective, and it is used to form the UHSS A-pillar of auto body to verify the reliability of results.

\section{Materials and Methods}

2.1. Materials. The material used in this experiment is BR1500HS. The thickness of the experimental material is $1.8 \mathrm{~mm}$. The chemical composition (wt\%) of BR1500HS is shown in Table 1.

It should be paid attention that there are amounts of boron (B) in BR1500HS, which could expedite the martensite transformation and improve the hardenability of steel.

2.1.1. Microstructure and Mechanical Properties of the Materials. The original microstructure of BR1500HS is shown in Figure 1. It shows a typical low carbon steel banded structure, which leads to anisotropy mechanics. The tensile strength and elongation of parallel direction are superior to the vertical direction. In order to ensure whether the strength of the hot forming parts meets the requirements, standard tensile samples are cut perpendicular to the rolling direction as shown in Figure 2. The stress-strain curve of original material BR1500HS is obtained at room temperature, as shown in Figure 3. It can be seen that the yield strength and the tensile strength of BR1500HS are $462 \mathrm{MPa}$ and $627 \mathrm{MPa}$, respectively.
TABle 1: B1500HS composition (wt\%).

\begin{tabular}{lcccccccc}
\hline $\mathrm{C}$ & $\mathrm{Si}$ & $\mathrm{Mn}$ & $\mathrm{P}$ & $\mathrm{S}$ & $\mathrm{Cr}$ & $\mathrm{B}$ & $\mathrm{Al}$ & $\mathrm{Ti}$ \\
\hline 0.21 & 0.27 & 1.33 & 0.0098 & 0.0011 & 0.12 & 0.0023 & 0.039 & 0.047 \\
\hline
\end{tabular}

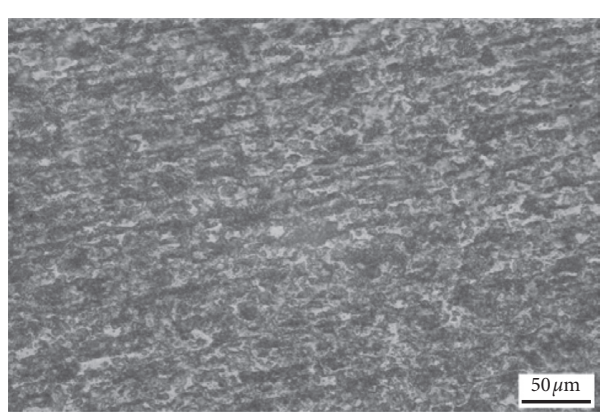

FIgURE 1: Microstructure of BR1500HS boron alloy steel at room temperature.

2.1.2. Forming Performance of the Materials. The main factors influencing the hot stamping performance of UHSS are material hardening exponent and rolling of anisotropy $[14,21]$. The plasticity of BR1500HS at high temperature is rather much better, and the elongation can reach up to $50 \%$. But there are still many fractures when forming complex components such as A-pillar as shown in Figure 4. This is because there are uneven deformation distribution, local thinning, as well as fracture.

2.2. Experimental Methods. In order to clarify the effect of austenite and quenching on mechanical properties of materials accurately, effects of cooling rate are investigated firstly in this paper. Austenite temperature and holding time are studied by multiobjective optimization.

2.2.1. Cooling Rate Tests. As for UHSS, homogeneous quenching in the mould is hard to realize because it easily leads to inhomogeneous mechanical properties. The cooling rate is an important parameter during the hot stamping of UHSS. It can affect the quality of forming parts directly. In this paper, the effect of different cooling rates on mechanical properties of UHSS is investigated, in order to determine the best cooling rate range for BR1500HS in the mould.

Different cooling rates are studied in this paper, as shown in Table 2. Gleeble 1500 thermal simulation testing machine is used as shown in Figure 5(a). The test method as shown in Figure 5(b) is as follows: (1) samples are heated to $950{ }^{\circ} \mathrm{C}$ at $10^{\circ} \mathrm{C} / \mathrm{s}$; (2) samples are put into the heating furnace for $120 \mathrm{~s}$ to make them fully austenite; (3) the heating sample is cooled down to $850^{\circ} \mathrm{C}$ at $30^{\circ} \mathrm{C} / \mathrm{s}$ and kept heating preservation for 10s; (4) tensile experiment is conducted for each sample at a strain rate of $0.3 \mathrm{~s}^{-1}$ to a true strain of 0.2 with Gleeble 1500; and (5) these samples are cooled down at a cooling rate of $20^{\circ} \mathrm{C} / \mathrm{s}, 30^{\circ} \mathrm{C} / \mathrm{s}, 40^{\circ} \mathrm{C} / \mathrm{s}, 50^{\circ} \mathrm{C} / \mathrm{s}, 70^{\circ} \mathrm{C} / \mathrm{s}$, and $100^{\circ} \mathrm{C} / \mathrm{s}$ to room temperature, respectively. Effects of cooling rate could be concluded by observing the microstructure of these samples. 

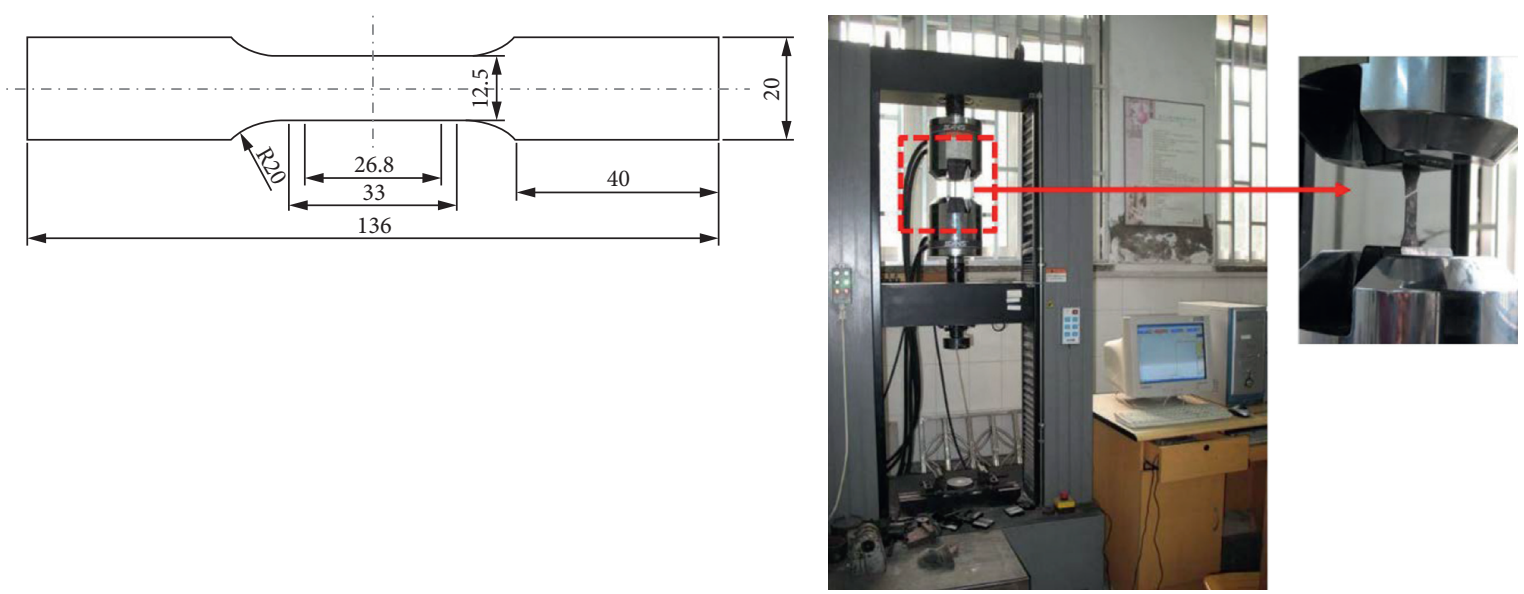

(a)

(b)

Figure 2: Specimen of the tensile test: (a) specimen size and (b) tensile device.

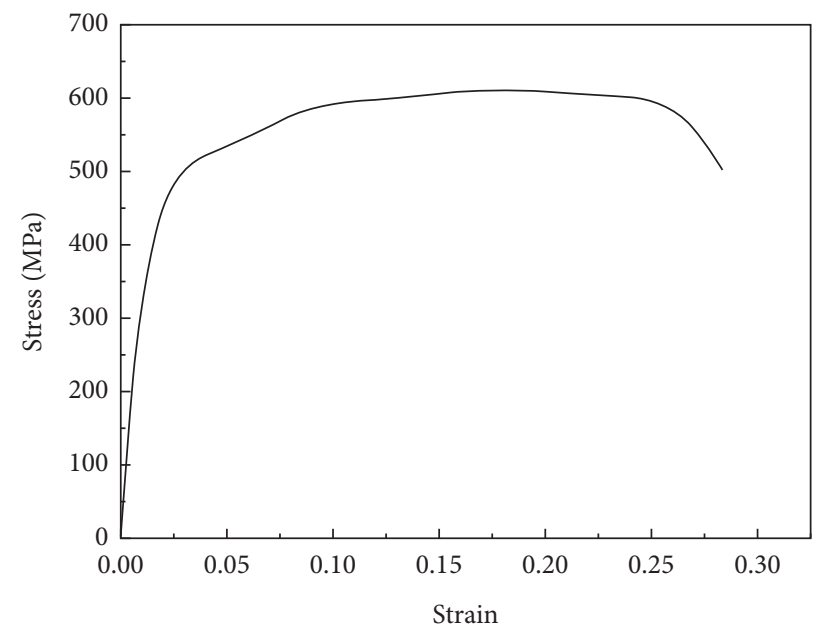

FIgURE 3: True stress-strain curve of BR1500HS at room temperature.
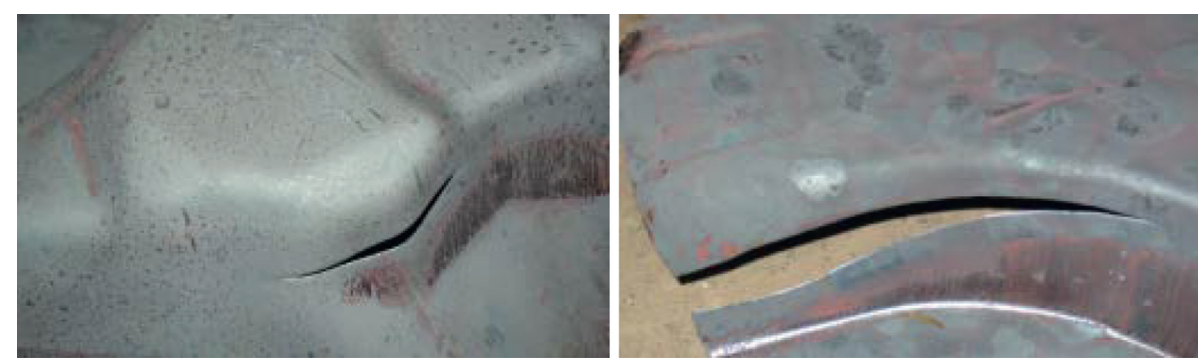

Figure 4: Fractures of the A-pillar during hot stamping.

2.2.2. Multiobjective Optimization Design. In order to investigate the effects of austenite temperature and holding time on mechanical properties of BR1500HS, the experimental schemes for these two variables are confirmed as shown in Table 3 , where $\theta\left({ }^{\circ} \mathrm{C}\right)$ and $t(\mathrm{~min})$ represented austenite temperature and the holding time, respectively.
And the actual experimental procedure included: (i) heating the samples according to the set temperatures and holding time, (ii) transferring the samples into the hot forming mould through water-cooling channels, (iii) cooling the samples at about $30^{\circ} \mathrm{C} / \mathrm{s}$ in the mould, and (iv) analyzing the mechanical properties of samples with Rockwell hardness test system and tensile test system. Then, the 
TABLE 2: Specimen of experiment design.

\begin{tabular}{lcccc}
\hline No. & Experimental temperature $\left({ }^{\circ} \mathrm{C}\right)$ & Strain rate $\left(\mathrm{s}^{-1}\right)$ & True strain & Cooling rate $\left({ }^{\circ} \mathrm{C} / \mathrm{s}\right)$ \\
\hline 1 & 850 & 0.3 & 0.2 & 20 \\
3 & 850 & 0.3 & 0.2 & 30 \\
5 & 850 & 0.3 & 0.2 & 40 \\
7 & 850 & 0.3 & 0.2 & 50 \\
9 & 850 & 0.3 & 0.2 & 70 \\
11 & 850 & 0.3 & 0.2 & 100 \\
\hline
\end{tabular}

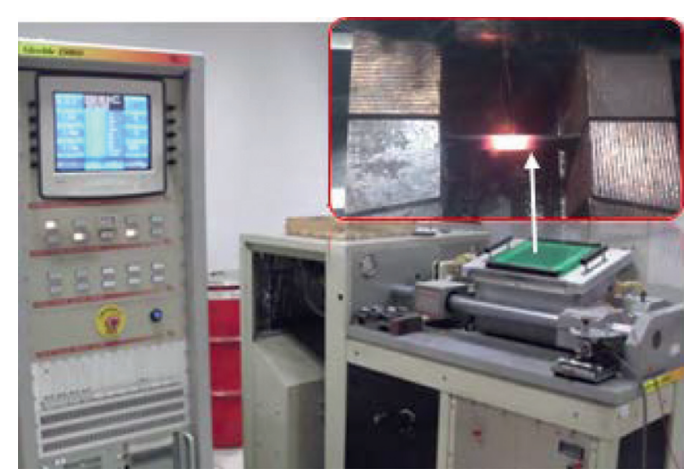

(a)

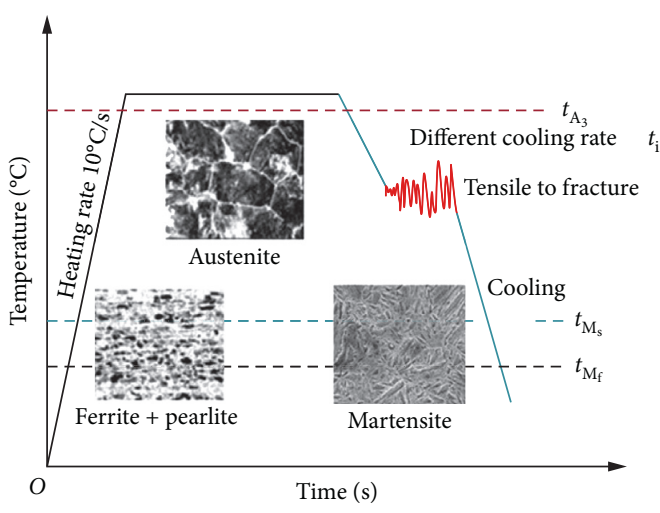

(b)

FIGURE 5: Heating device and test method: (a) Gleeble 1500 and (b) heating and cooling method.

TABLE 3: Experimental results.

\begin{tabular}{lccccc}
\hline No. & $\theta\left({ }^{\circ} \mathrm{C}\right)$ & $t(\mathrm{~min})$ & $H(\mathrm{HRC})$ & $\sigma(\mathrm{MPa})$ & $\delta(\%)$ \\
\hline 1 & 800.00 & 4.00 & 39.8 & $1,123.86$ & 8.87 \\
2 & 850.00 & 2.00 & 49.8 & $1,521.08$ & 9.65 \\
3 & 850.00 & 6.00 & 45.3 & $1,492.53$ & 9.69 \\
4 & 900.00 & 0.00 & 51.8 & $1,601.32$ & 11.16 \\
5 & 900.00 & 8.00 & 47.2 & $1,514.56$ & 9.73 \\
6 & 900.00 & 4.00 & 50.3 & $1,572.56$ & 11.83 \\
7 & 900.00 & 4.00 & 50.3 & $1,572.56$ & 11.83 \\
8 & 900.00 & 4.00 & 50.3 & $1,572.56$ & 11.83 \\
9 & 900.00 & 4.00 & 50.3 & $1,572.56$ & 11.83 \\
10 & 900.00 & 4.00 & 50.3 & $1,572.56$ & 11.83 \\
11 & 950.00 & 6.00 & 48.6 & $1,518.61$ & 10.36 \\
12 & 950.00 & 2.00 & 48.9 & $1,532.54$ & 10.98 \\
13 & $1,000.00$ & 4.00 & 47.5 & $1,124.67$ & 7.76 \\
\hline
\end{tabular}

experimental results could be attained as shown in Table 3. In this table, $H(\mathrm{HRC}), \sigma(\mathrm{MPa})$, and $\delta(\%)$ represent quenching hardness, tensile strength, and elongation, respectively.

\section{Results and Discussions}

\subsection{The Effect of Cooling Rate}

3.1.1. The Effect of Cooling Rate on Hardness. Three-row test points of each sample at different cooling rates are selected to test hardness. The average value is taken as the hardness of BR1500HS samples as shown in Table 4.
TABLE 4: Hardness of BR1500HS at different cooling rates.

\begin{tabular}{lcc}
\hline No. & Cooling rate $\left({ }^{\circ} \mathrm{C} . \mathrm{s}^{-1}\right)$ & Hardness (HRC) \\
\hline 1 & 20 & 42.3 \\
2 & 30 & 45.8 \\
3 & 40 & 50.2 \\
4 & 50 & 51.3 \\
5 & 70 & 52.1 \\
6 & 100 & 52.5 \\
\hline
\end{tabular}

As shown in Table 4, the hardness of samples is minimum at the cooling rate of $20^{\circ} \mathrm{C} / \mathrm{s}$, while the hardness of samples at the cooling rate of $100{ }^{\circ} \mathrm{C} / \mathrm{s}$ is maximum. It indicates that the hardness increases with elevating cooling rate.

3.1.2. Effect of Cooling Rate on Microstructure. The etching solution used for microstructure is made by distributing hydrochloric acid and alcohol in a certain proportion. Final microstructures of samples at different cooling rates are shown in Figure 6. It can be seen that although the main phase is martensite, the content of martensite is varied for different samples. Normally, the martensite content of samples increases with the cooling rate, which leads to higher hardness. So the maximum hardness value appears at a cooling rate of $100^{\circ} \mathrm{C} / \mathrm{s}$ corresponding to the maximum content of martensite. Moreover, when the cooling rate is higher than $27^{\circ} \mathrm{C} / \mathrm{s}$, there will be second-phase bainite with a small amount [17]. As the cooling rate increases, the content of martensite increases. But there are little in the bainite phase which exists from Figures 6(b) 6(f). 


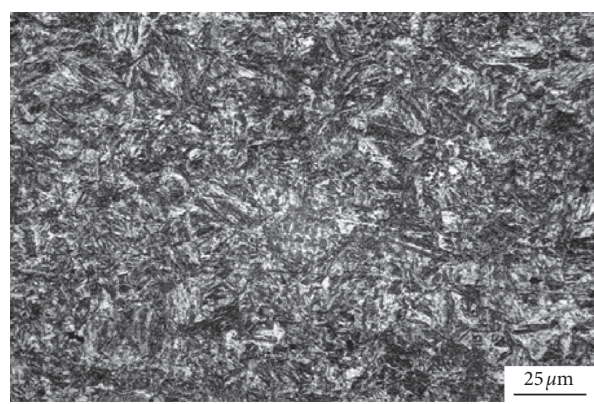

(a)

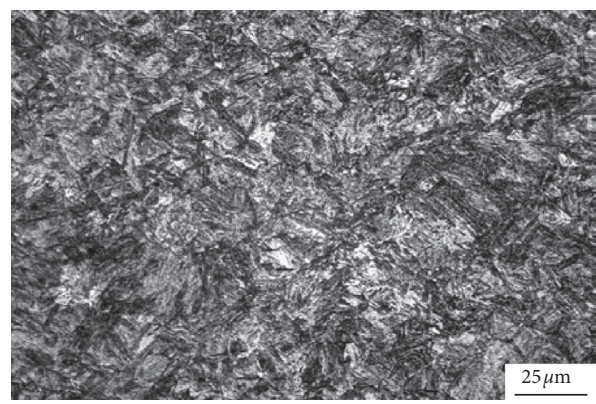

(c)

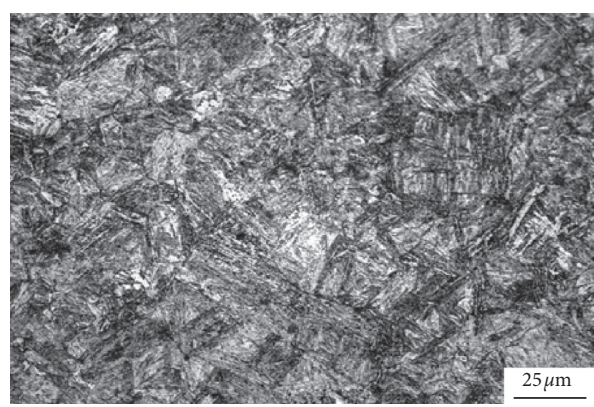

(e)

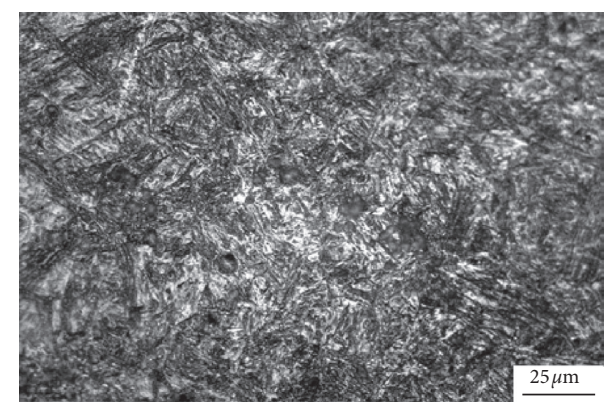

(b)

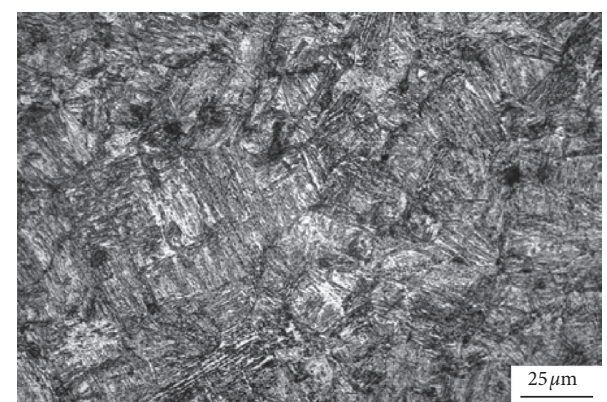

(d)

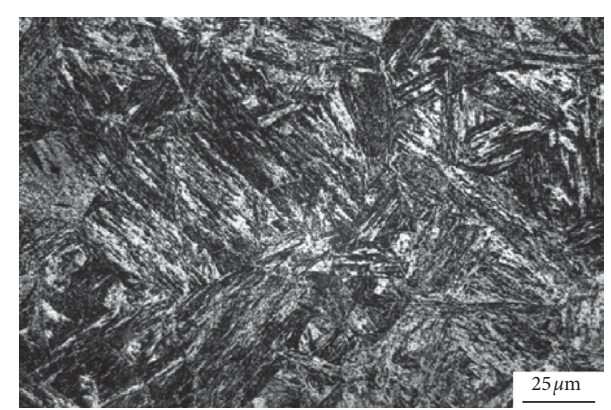

(f)

Figure 6: Microstructure of BR1500HS under different cooling rate: (a) $20^{\circ} \mathrm{C} / \mathrm{s}$, (b) $30^{\circ} \mathrm{C} / \mathrm{s}$, (c) $40^{\circ} \mathrm{C} / \mathrm{s}$, (d) $50^{\circ} \mathrm{C} / \mathrm{s}$, (e) $70^{\circ} \mathrm{C} / \mathrm{s}$, and (f) $100^{\circ} \mathrm{C} / \mathrm{s}$.

3.2. Regression Model of Responses. RSM is usually used to explore the relationships between explanatory and response variables. The relationship can be founded by polynomial functions and further displayed in the graphics.

Using the response surface method, the fitting equation of quenching hardness is obtained according to Table 3.
These equations (1)-(3) should be clearly given because they are only suitable at a cooling rate of $30^{\circ} \mathrm{C} / \mathrm{s}$. The regression response surface models of the quenching hardness $H$, the strength of extension $\sigma$, and the elongation $\delta$ are expressed as follows:

$$
\begin{gathered}
H=-477.422+1.188236 \times T-9.62342 \times t+0.0105 \times T \times t-0.00067 \times T^{2}-0.05124 \times t^{2}, \\
\sigma=-34293.1+79.8753 \times T-36.6319 \times t+0.03655 \times T \times t-0.04442 \times T^{2}-0.65789 \times t^{2}, \\
\delta=-281.887+0.644333 \times T+2.049167 \times t-0.00165 \times T \times t-0.00035 \times T^{2}-0.08844 \times t^{2},
\end{gathered}
$$

where $T\left({ }^{\circ} \mathrm{C}\right)$ represents the austenite temperature and $t$ ( $\mathrm{min}$ ) represents the holding time. The regression equations (1)-(3) can show approximate relationships between response and independent variables. The fitted formulas can be applied to predict the values of the quenching hardness $H$, the tensile strength $\sigma$, and the elongation $\delta$. The difference between the predicted and the experimental values is shown in Figure 7. The comparison results imply that the predicted values of $H, \sigma$, and $\delta$ are close to the experimental values within a $95 \%$ confidence interval. 


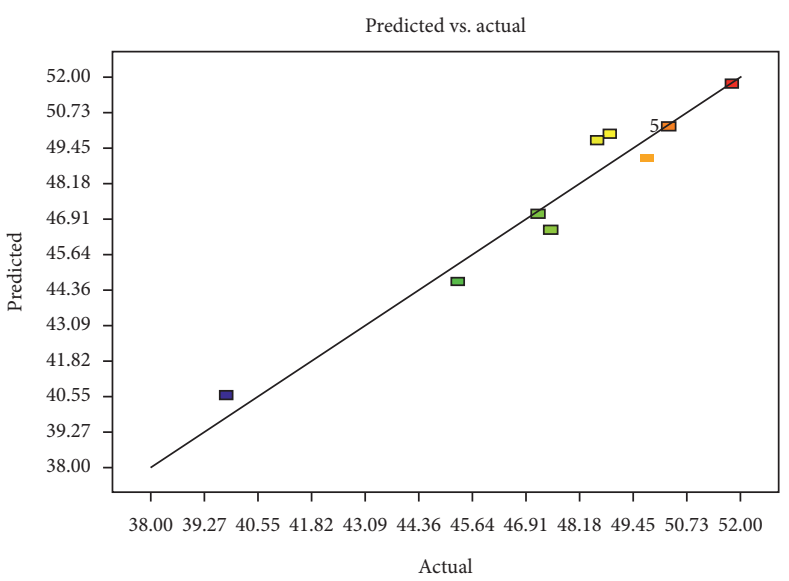

(a)

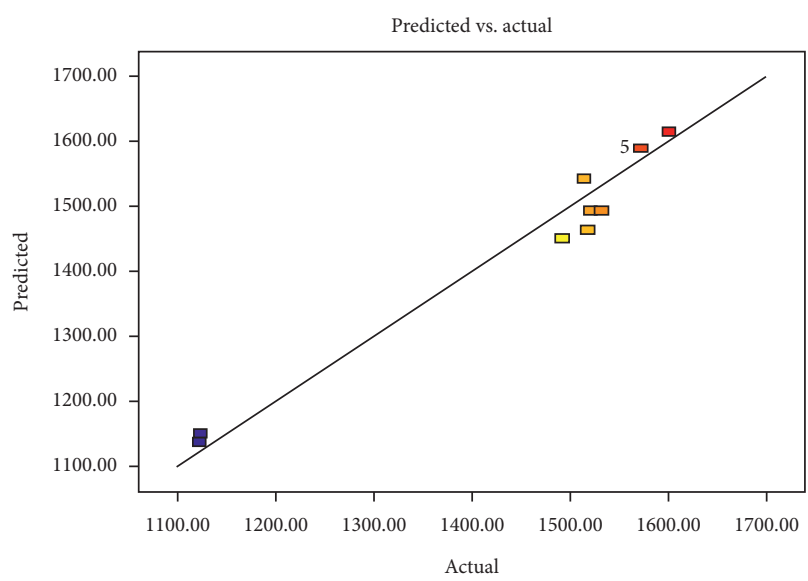

(b)

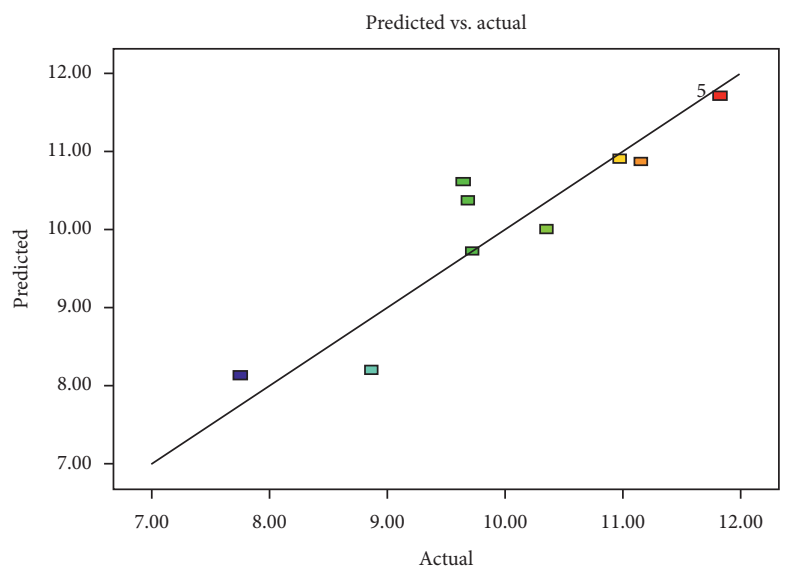

(c)

Figure 7: Comparisons of the predicted and experimental values: (a) quenching hardness $H$, (b) tensile strength $\sigma$, and (c) elongation $\delta$.

3.3. Analysis of the Mathematical Model. To evaluate the reliability of the experimental results and the credibility of the responses model, both the statistical significance of the regression models and the statistical significance on the individual model coefficients should be tested. These tests are performed according to the ANOVA procedure by calculating the " $F$ value", the " $P$ value", the total determination coefficient $\left(R^{2}\right)$, the adjusted determination coefficient $\left(\bar{R}^{2}\right)$, as well as the Adeq precision $[14,22,23]$.

Usually, the desired confidence level is set as $99 \%$. If the $P$ value is smaller than 0.01 , the regression model is considered to be statistically significant, and the variables in the model have significant effects on the responses. When $R^{2}$ approaches unity, the better the response model fits the actual data, the less the difference between the predicted and actual values exists. Therefore, the bigger the value of $\bar{R}^{2}$ is, the better the regression effects are. Meanwhile, the model is available with adequate definition when the Adeq precision is bigger than 4. Thus, the bigger the value of Adeq precision is, the better the regression effects are.
3.3.1. Analysis of Variance (ANOVA) for Quenching Hardness. The analysis of variance (ANOVA) results of the quenching hardness model is presented in Table 5. It shows that the lack of fit is 4.916351. So there is no need to charge or simplify it to improve the $R^{2}$. Meanwhile, it can be known that $T, t, T \times t, T^{2}$, and $t^{2}$ are the main factors that affect the response value. $P$ value of each item is very small, indicating that the terms in the model have a significant effect on the quenching hardness.

The model $F$ value is $32.07949\left(F>F_{0.01}(9,7)=6.72\right)$. The model $P$ value is 0.0001 , which is far less than 0.01 . Both of them demonstrate that the regression result is very significant. The adjusted determination coefficient $\left(\bar{R}^{2}\right)$ is 0.9283 , which implies that $92.83 \%$ of the changes of the response value are attributed to the independent variables. The total determination coefficient $\left(R^{2}\right)$ is 0.9582 . It shows that the predicted and experimental values have high relativity. It implies that the polynomial model can represent the experimental results adequately. There is little difference between the adjusted determination coefficient $\left(\bar{R}^{2}\right)$ and the total determination coefficient $\left(R^{2}\right)$. It is not necessary to 
TABLE 5: Analysis of variance (ANOVA) for the quenching hardness.

\begin{tabular}{|c|c|c|c|c|c|}
\hline Source & Sum of squares & Free degree & Mean square & $F$ value & $P$ value \\
\hline Model & 117.33 & 5 & 22.53058 & 32.07949 & 0.0001 \\
\hline$T$ & 112.6529 & 1 & 26.40333 & 37.5936 & 0.0005 \\
\hline$t$ & 26.40333 & 1 & 16.33333 & 23.25573 & 0.0019 \\
\hline$T \times t$ & 16.33333 & 1 & 4.41 & 6.279048 & 0.0406 \\
\hline$T^{2}$ & 4.41 & 1 & 63.7092 & 90.71046 & $<0.0001$ \\
\hline$t^{2}$ & 63.7092 & 1 & 0.962538 & 1.370482 & 0.2800 \\
\hline Residual & 4.916351 & 7 & 0.702336 & - & - \\
\hline Lack of fit & 4.916351 & 3 & 1.638784 & - & - \\
\hline Pure error & 0 & 4 & - & - & - \\
\hline Cor total & 117.5692 & 12 & - & - & - \\
\hline$R^{2}=0.9582$ & $\bar{R}^{2}=0.9283$ & \multicolumn{2}{|c|}{ Pred $R^{2}=\mathbf{0 . 5 8 0 8}$} & \multicolumn{2}{|c|}{ Adeq precision $=\mathbf{1 9 . 5 8 4}$} \\
\hline
\end{tabular}

optimize the response model further. Meanwhile, the Adeq precision is 19.584. This model has an adequate definition. Model is available when the Adeq precision is bigger than 4 . Therefore, equation (1) is suitable for analyzing and predicting the quenching hardness.

3.3.2. Analysis of Variance (ANOVA) for the Tensile Strength. The analysis of variance (ANOVA) results of the tensile strength model is shown in Table 6 . The model $F$ value is $41.90669\left(>\mathrm{F}_{0.01}(9,7)=6.72\right)$, and the model $P$ value is 0.0001 , which is far less than 0.01 . Both the $F$ and the $P$ values demonstrate that the regression result is very significant. The adjusted determination coefficient $\left(\bar{R}^{2}\right)$ is 0.9446 , which implies that $94.46 \%$ of the changes of the response value are attributed to the independent variables. The total determination coefficient $\left(R^{2}\right)$ is 0.9783 , suggesting the high relativity of the predicted and experimental values, which implies that the polynomial model can represent the experimental results adequately. Meanwhile, the Adeq precision is 18.299 (Adeq precision > 4), suggesting that this model has an adequate definition. Therefore, equation (2) is suitable for analyzing and predicting the tensile strength.

3.3.3. Analysis of Variance (ANOVA) for the Elongation. The analysis of variance (ANOVA) results of the elongation model is shown in Table 7 . The lack of fit is 2.254433. There is no need to charge or simplify it to improve the $R^{2}$. Meanwhile, the $P$ value of each item is less than significance level $\alpha(\alpha=0.05)$. It indicates that the terms in the model have a significant effect on the quenching hardness.

As can be seen from the ANOVA results, the model $F$ value is $12.02011\left(F>F_{0.01}(9,7)=6.72\right)$. The model $P$ value is 0.0025 , which is far less than 0.01 . It can be said that the regression result is very significant. The adjusted determination coefficient $\left(\bar{R}^{2}\right)$ is 0.8212 , which implies that $82.12 \%$ of the changes of the response values are attributed to the independent variables. The total determination coefficient $\left(R^{2}\right)$ is 0.8957 . The predicted and the experimental values have a high correlation. It implies that the polynomial model can represent the experimental results adequately. Meanwhile, the Adeq precision is 9.290 (Adeq precision $>4$ ). This model has an adequate definition. Therefore, equation (3) is suitable for analyzing and predicting elongation.

3.4. Response Surface Analysis. To visualize the effect of the variables on the required responses, the $3 \mathrm{D}$ response surface and $2 \mathrm{D}$ contours are applied to describe the regression equations. The corresponding $3 \mathrm{D}$ response surfaces and $2 \mathrm{D}$ contours for quenching hardness, tensile strength, and elongation of BR1500HS are shown in Figures 6-8.

3.4.1. Response Surface Analysis for Quenching Hardness. The $3 \mathrm{D}$ response surface and $2 \mathrm{D}$ contour plot of the specimen for quenching hardness are shown in Figure 8. It can be seen that at the temperature range from $850^{\circ} \mathrm{C}$ to $900^{\circ} \mathrm{C}$, the quenching hardness increases significantly with decreasing holding time. When the holding time is $0 \mathrm{~min}$, the quenching hardness reaches maximum and then drops down with the increasing austenite temperature. Moreover, the maximum value of quenching hardness appears at $887^{\circ} \mathrm{C}$, and the holding time is $0-2 \mathrm{~min}$.

The Table 8 of the data is obtained by equation (1). Here, $\mathrm{H}$ represents hardness.

3.4.2. Response Surface Analysis for Tensile Strength. 3D response surface and 2D contour plot of specimen for tensile strength based on equation (2) are shown in Figure 9. It can be seen that there is a peak in the region temperature from $875^{\circ} \mathrm{C}$ to $925^{\circ} \mathrm{C}$, and the holding time varies from $0 \mathrm{~min}$ to $2 \mathrm{~min}$.

The function equation (2) is used as the single-objective model to find out the optimum values in the specific region. There are two maximum values for tensile strength. One is at $900^{\circ} \mathrm{C}$ with a holding time of $2 \mathrm{~min}$. The other is at $919.2^{\circ} \mathrm{C}$ with a holding time of $0-2 \mathrm{~min}$. The maximum value is shown in Table 9.

3.4.3. Response Surface Analysis for Elongation. 3D response surface and 2D contour plot for tensile strength based on equation (3) are shown in Figure 10. It can be seen that there is a peak in the region from $875^{\circ} \mathrm{C}$ to $925^{\circ} \mathrm{C}$, and the holding 
TABLE 6: Analysis of variance (ANOVA) for the tensile strength.

\begin{tabular}{|c|c|c|c|c|c|}
\hline Source & Sum of squares & Free degree & Mean square & $F$ value & $P$ value \\
\hline Model & $307,461.3$ & 5 & $61,492.26$ & 41.90669 & $<0.0001$ \\
\hline$T$ & 127.7921 & 1 & 127.7921 & 0.08709 & 0.7765 \\
\hline$t$ & 3,888 & 1 & 3,888 & 2.649654 & 0.1476 \\
\hline$T \times t$ & 53.4361 & 1 & 53.4361 & 0.036416 & 0.8541 \\
\hline$T^{2}$ & $282,574.3$ & 1 & $282,574.3$ & 192.5731 & $<0.0001$ \\
\hline$t^{2}$ & 158.6806 & 1 & 158.6806 & 0.10814 & 0.7519 \\
\hline Residual & 5.537932 & 7 & 0.79113314 & - & - \\
\hline Lack of fit & 5.537932 & 3 & 1.84597733 & - & - \\
\hline Pure error & 0 & 4 & 0 & - & - \\
\hline Cor total & $317,732.8$ & 12 & - & - & - \\
\hline$R^{2}=0.9677$ & $\bar{R}^{2}=0.9446$ & \multicolumn{2}{|c|}{ Pred $R^{2}=\mathbf{0 . 7 7 3 8}$} & \multicolumn{2}{|c|}{ Adeq precision $=\mathbf{1 8 . 2 9 9}$} \\
\hline
\end{tabular}

TABLE 7: Analysis of variance (ANOVA) for the elongation.

\begin{tabular}{|c|c|c|c|c|c|}
\hline Source & Sum of squares & Free degree & Mean square & $F$ value & $P$ value \\
\hline Model & 19.35609 & 5 & 3.871218 & 12.02011 & 0.0025 \\
\hline$T$ & 0.004033 & 1 & 0.004033 & 0.012523 & 0.9140 \\
\hline$t$ & 0.986133 & 1 & 0.986133 & 3.061937 & 0.1236 \\
\hline$T \times t$ & 0.1089 & 1 & 0.1089 & 0.338134 & 0.5791 \\
\hline$T^{2}$ & 17.99722 & 1 & 17.99722 & 55.88125 & 0.0001 \\
\hline$t^{2}$ & 2.867384 & 1 & 2.867384 & 8.903207 & 0.0204 \\
\hline Residual & 2.254433 & 7 & 0.322062 & - & - \\
\hline Lack of fit & 2.254433 & 3 & 0.751478 & - & - \\
\hline Pure error & 0 & 4 & 0 & - & - \\
\hline Cor total & 21.61052 & 12 & - & - & - \\
\hline$R^{2}=0.8957$ & $\bar{R}^{2}=0.8212$ & \multicolumn{2}{|c|}{ Pred $R^{2}=\mathbf{0 . 0 1 9 1}$} & \multicolumn{2}{|c|}{ Adeq precision $=\mathbf{9 . 2 9 0}$} \\
\hline
\end{tabular}

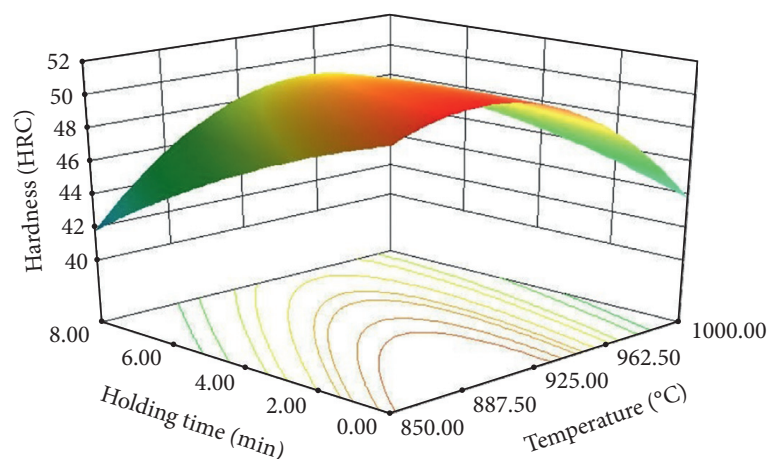

(a)

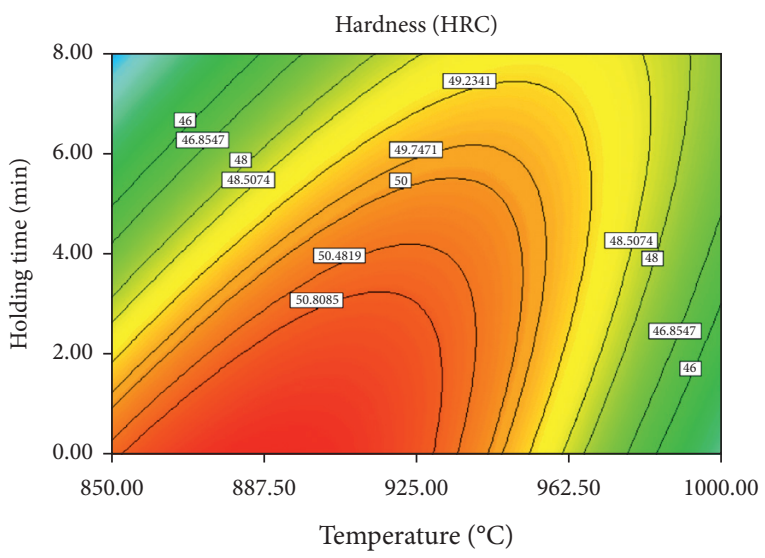

(b)

Figure 8: (a) 3D response surface for quenching hardness and (b) 2D contour for quenching hardness.

TABLE 8: Optimum values for quenching hardness.

\begin{tabular}{lccc}
\hline Parameters & $\theta\left({ }^{\circ} \mathrm{C}\right)$ & $t(\min )$ & $H(\mathrm{HRC})$ \\
\hline Optimum value & 887 & 1 & 51.8 \\
\hline
\end{tabular}




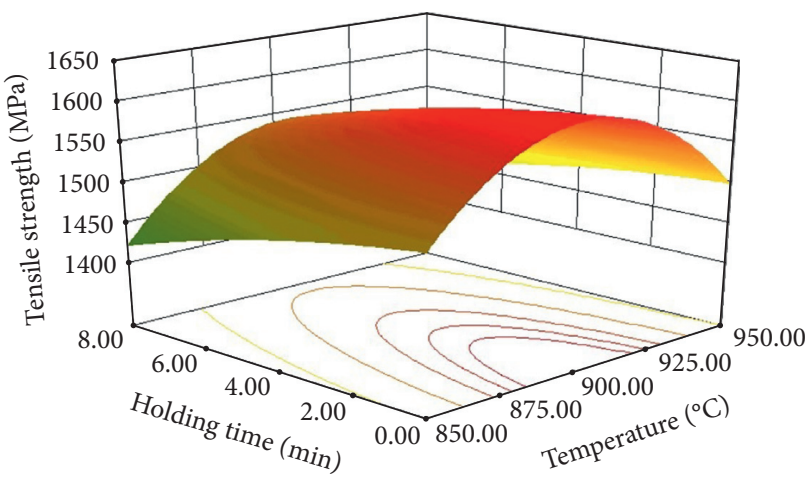

(a)

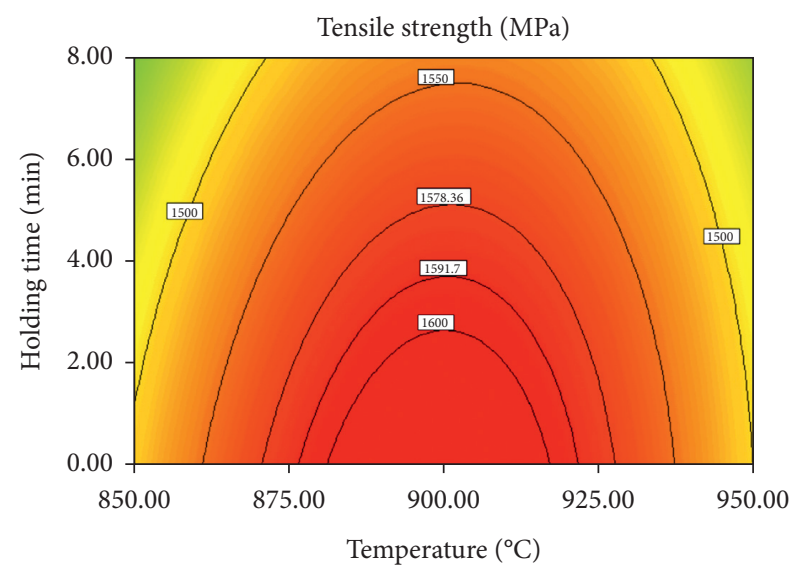

(b)

Figure 9: (a) 3D response surface for tensile strength and (b) 2D contour for tensile strength.

TABLe 9: Maximum values for tensile strength.

\begin{tabular}{lccc}
\hline Parameters & $\theta\left({ }^{\circ} \mathrm{C}\right)$ & $t(\min )$ & $\sigma(\mathrm{MPa})$ \\
\hline \multirow{2}{*}{ Optimum value } & $900^{\circ} \mathrm{C}$ & 2 & $1,621.64$ \\
& 919.2 & 0 & $1,640.40$ \\
\hline
\end{tabular}

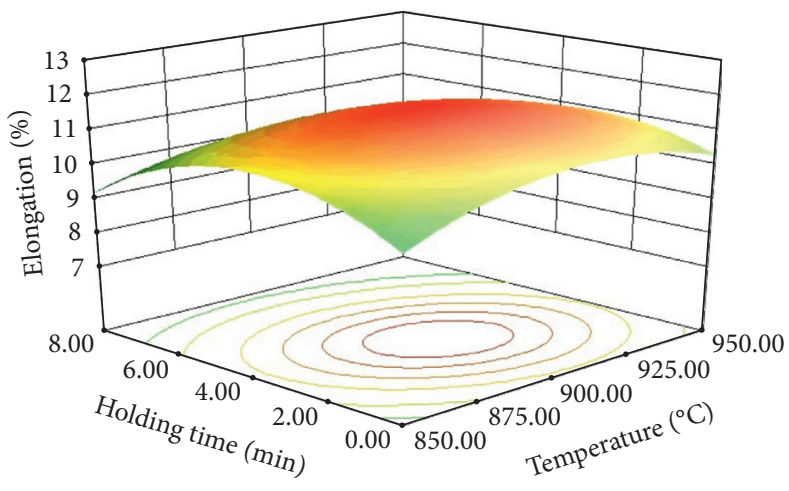

(a)

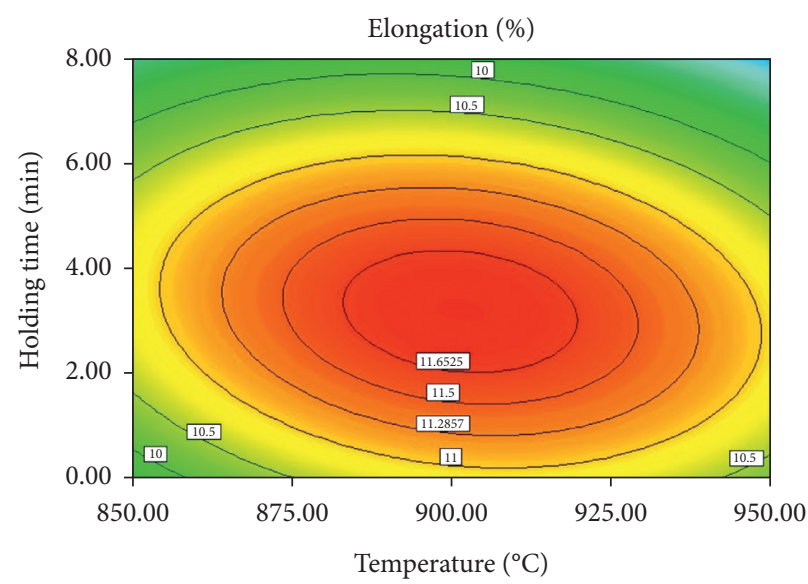

(b)

FIGURE 10: (a) 3D response surface for elongation and (b) 2D contour for elongation.

time varies from $2 \mathrm{~min}$ to $4 \mathrm{~min}$. In this region, there is only one maximum value.

The superior elongation exists at $900^{\circ} \mathrm{C}$, and the holding time is $2-4 \mathrm{~min}$. The function equation (3) is used as the single-objective model to find out the optimum values in the optimum region, as shown in Table 10.

3.5. Multiobjective Optimization. Generally, the parts are made of UHSS that is served as reinforcement in the car body. Hence, the more superior the mechanical properties are, such as quenching hardness, tensile strength, and elongation, the better the quality of the product is. In this
TABle 10: Optimum values for elongation.

\begin{tabular}{lccc}
\hline Parameters & $\theta\left({ }^{\circ} \mathrm{C}\right)$ & $t(\min )$ & $\delta(\%)$ \\
\hline Optimum value & 900 & 3 & 11.83 \\
\hline
\end{tabular}

paper, the RSM method is chosen to find the solution to this multiobjective program. The quenching hardness, tensile strength, as well as elongation are taken as target variables; tensile strength is the main target. There are corresponding requirements about the optimal parameters; they are quenching hardness, tensile strength, and elongation. These 
TABLE 11: Global optimum values.

\begin{tabular}{lcccrr}
\hline Parameters & $T\left({ }^{\circ} \mathrm{C}\right)$ & $t(\min )$ & $H(\mathrm{HRC})$ & $\sigma(\mathrm{MPa})$ & $\delta(\%)$ \\
\hline Optimum value & 906.5 & 0 & 50.76 & $1,589.7$ & 10.96 \\
\hline
\end{tabular}

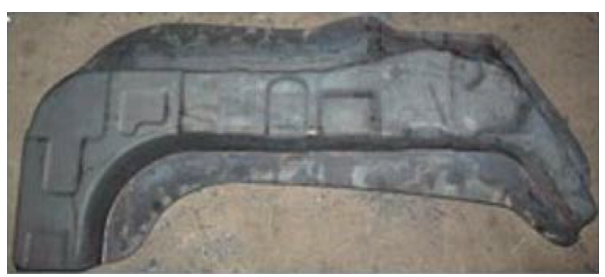

FIgURE 11: A-pillar after multiobjective optimization.

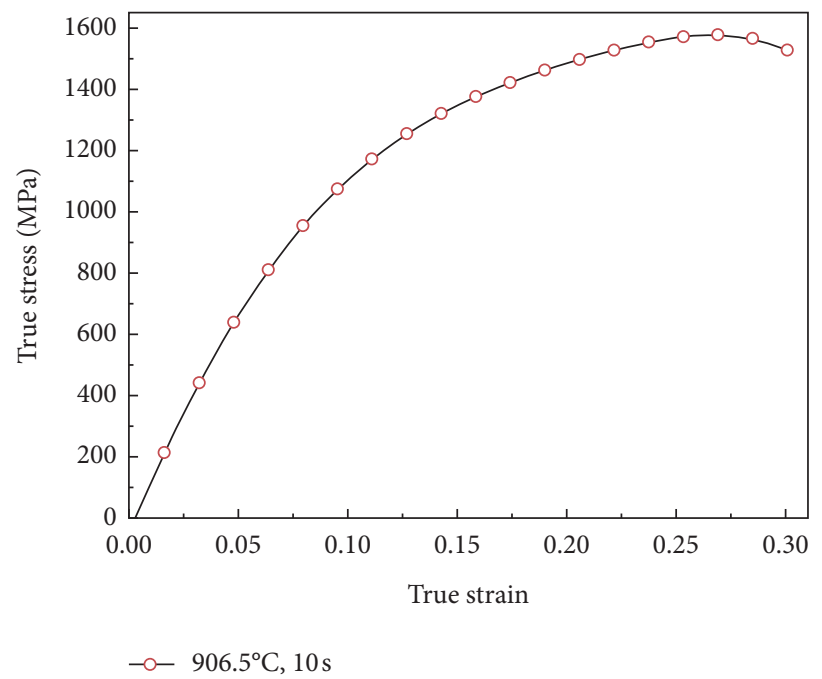

Figure 12: True stress-strain curve of the tensile sample.

parameters should be greater than $50 \mathrm{HR}, 1,600 \mathrm{MPa}$, and $8 \%$, respectively. Therefore, the simultaneous equations of the objectives $H(\theta, t), \sigma(\theta, t)$, and $\delta(\theta, t)$ are written as follows:

$$
\begin{cases}\max H(T, t)=H^{*} & \text { s.t. } 800 \leq T \leq 950 \\ \max \sigma(T, t)=\sigma^{*} & 0 \leq t \leq 8 \\ \max \delta(T, t)=\delta^{*} & \end{cases}
$$

The value of $H^{*}, \sigma^{*}$, and $\delta^{*}$ can be gained by solving equation (4). Vector $f_{i}^{*}=\left(H^{*}, \sigma^{*}, \delta^{*}\right)^{T}$ is seen as the ideal point, which is difficult to realize because of the complexity among objectives. An evaluation function $\varphi(z)$ must be defined to find a point that approaches the ideal point mostly as follows:

$$
\phi(z)=\sqrt{\sum_{i}^{p}\left(z_{i}-f_{i}^{*}\right)^{2}}
$$

According to the optimization procedures, the evaluation function $f(z)$ should be minimized as follows:

$$
\left\{\begin{array}{l}
\min \phi=(H, \sigma, \delta)=\sqrt{\left(H(T, t)-H^{*}\right)^{2}+\left(\sigma(T, t)-\sigma^{*}\right)^{2}+\left(\delta(T, t)-\delta^{*}\right)^{2}} \\
\text { s.t. } \quad 800 \leq T \leq 950, \\
0 \leq t \leq 8 .
\end{array}\right.
$$

By solving equations (4)-(6), the global optimum values are obtained, which are presented in Table 11.

Multiobjective optimization results show that the predicted quenching hardness, tensile strength, and elongation of BR1500HS are not less than $50.76 \mathrm{HRC}$, $1,589.7 \mathrm{MPa}$, and $10.96 \%$, respectively, when the austenite temperature is $906.5^{\circ} \mathrm{C}$, and the holding time is more than $0 \mathrm{~min}$. 
TABLE 12: Results of testing according to the optimal design.

\begin{tabular}{lccccc}
\hline Parameters & $\theta\left({ }^{\circ} \mathrm{C}\right)$ & $t(\mathrm{~min})$ & $H(\mathrm{HRC})$ & $\sigma(\mathrm{MPa})$ & $\delta(\%)$ \\
\hline Experimental value & 906.5 & 10 & 51.36 & $1,592.6$ & 9.82
\end{tabular}

3.6. Experimental Verification. The optimization result is applied to the actual production: (i) heating the performed part to $906.5^{\circ} \mathrm{C}$, (ii) holding it in this state for $10 \mathrm{~s}$ to promote full austenite, and (iii) cooling down at a cooling rate of $30^{\circ} \mathrm{C} / \mathrm{s}$ after final stamping. As shown in Figure 11, A-pillar without fracture is obtained using the optimization result.

In order to analyze the performance of the A-pillar, three positions are selected to test the quenching hardness, tensile strength, and elongation. The true stress-strain curve of these positions is shown in Figure 12. Experimental values of quenching hardness, tensile strength, and elongation are shown in Table 12.

Through a comparative analysis of experimental value (as shown in Table 12) and predicted value (as shown in Table 11), it could be concluded that the deviation between the experimental and the predicted values of quenching hardness and tensile strength are very little, $1.17 \%$ and $0.18 \%$, respectively. However, the deviation between the experimental and the predicted values of elongation is relatively large, that is, $11.6 \%$. It suggests that the result of multiobjective optimization has significant guidance on the process design of BR1500HS.

\section{Conclusions}

In this study, a number of experiments are performed. Experimental and statistical analyses on process parameters are carried out. The experiments are designed through RSM and obtained optimal values of quenching hardness, tensile strength, and elongation. This study aims to obtain optimal parameters. Hot forming of BR1500HS is widely used in industry due to the inaccuracy of process parameters. The workpiece has many flaws during hot forming. Confirmation experiments are conducted to assess the validity of the optimization. In conclusion, the following results are obtained:

(i) When the cooling rate reaches $30^{\circ} \mathrm{C} / \mathrm{s}$, the martensite content in microstructure reaches up to $95 \%$, and it has good comprehensive mechanical properties.

(ii) The most effective parameter on quenching hardness, tensile strength, and elongation is at the temperature of $887^{\circ} \mathrm{C}, 900^{\circ} \mathrm{C}$, and $919.2^{\circ} \mathrm{C}$, respectively, and the holding time is $0 \sim 2 \mathrm{~min}, 0 \sim 2 \mathrm{~min}$, and $2 \sim 4 \mathrm{~min}$, respectively.

(iii) When the material is heating to $887^{\circ} \mathrm{C}$ and the holding time is $1 \mathrm{~min}$, the peak value of quenching hardness reaches $51.8^{\circ} \mathrm{HRC}$. When the material is heating to $919.2^{\circ} \mathrm{C}$ and the holding time is $0 \mathrm{~min}$, the peak value of tensile strength reaches 1,640.4 MPa.

(iv) The results of multiobjective optimizations show that the global optimum value is gained at $906.5^{\circ} \mathrm{C}$ and the holding time is $0 \mathrm{~min}$. The predicted values of quenching hardness, tensile strength, and elongation are not less than $51.03 \mathrm{HRC}, 1,671 \mathrm{MPa}$, and $8.75 \%$, respectively.

As demonstrated by the optimization results, the RSM experimental design method was shown to have been successfully applied in the determination of the optimal process parameters for the hot forming of BR1500HS.

\section{Data Availability}

The original data used to support the findings of this study are available from the corresponding author upon request.

\section{Conflicts of Interest}

The authors declare that they have no conflict of interest.

\section{Acknowledgments}

The work reported in this paper was financially supported by the Natural Science Foundation of Guangdong Province -doctor initiated (no. 2017A030310621), professional core course construction "Stamping Process and Die Design" (no. 201902089), professional core curriculum construction "Mold Manufacturing Process" (no. 202002049), Key-Area Research and Development Program of Guangdong Province (no. 2020B090924002), the Additive Manufacturing Research Team (no. TDYB2019003), and Dongguan of Technology High-level Talents (Innovation Team) Research Project (no. KCYCXPT2016003).

\section{References}

[1] B. Alexander, M. J. Worswick, and M. A. Wells, "The influence of martensite, bainite and ferrite on the as-quenched constitutive response of simultaneously quenched and deformed boron steel- Experiments and model," Materials and Design, vol. 55, pp. 509-525, 2014.

[2] H. Wang, Bo Li, Z. Fan, and X. Li, "Numerical modeling of the hot forming process of composite materials," in Proceedings of the ASME 2019 14th International Manufacturing Science and Engineering Conference, Pennsylvania, USA, June 2019.

[3] Z. X. Gui, W. K. Liang, Y. Liu, and Y. S. Zhang, "Thermomechanical behavior of the Al-Si alloy coated hot stamping boron steel," Materials and Design, vol. 60, pp. 26-33, 2014.

[4] H. Li, L. He, G. Zhao, and L. Zhang, "Constitutive relationships of hot stamping boron steel B1500HS based on the modified Arrhenius and Johnson-Cook model," Materials Science and Engineering: A, vol. 580, pp. 330-348, 2013.

[5] N. Toshinobu and K. Nobusato, "Effect of quenching rate on hardness and microstructure of hot-stamped steel," Journal of Alloys and Compounds, vol. 577, pp. 549-554, 2013.

[6] E. Schoff, D. Schneider, N. Streichhan, T. Mittnacht, M. Selzer, and B. Nestler, "Multiphase-field modeling of martensitic phase transformation in a dual-phase microstructure," International Journal of Solids and Structures, vol. 134, pp. 181-194, 2017.

[7] E. Schoof, C. Herrmann, N. Streichhan, M. Selzer, D. Schneider, and B. Nestler, "On the multiphase-field modeling of martensitic phase transformation in dual-phase 
steel using J2-viscoplasticity," Modelling and Simulation in Materials Science and Engineering, vol. 27, Article ID 025010, 2019.

[8] M. Sarhil, "Constitutive relations and homogenization assumptions in phase-field models with elasticity: martensite transformation as an example," Master's thesis, University"at Duisburg-Essen and Ruhr-Universit"at Bochum, Bochum, Germany, 2018.

[9] B.-A. Behrens, J. Schröder, D. Brands et al., "Experimental and numerical investigations of the development of residual stresses in thermo-mechanically processed $\mathrm{Cr}$-alloyed steel 1.3505," Metals, vol. 9, no. 4, p. 480, 2019.

[10] D. Schneider, F. Schwab, E. Schoof et al., "On the stress calculation within phase-field approaches: a model for finite deformations," Computational Mechanics, vol. 60, no. 2, pp. 203-217, 2017.

[11] F. Kara, U. Köklü, and U. Kabasakaloğlu, "Taguchi optimization of surface roughness in grinding of cryogenically treated AISI 5140 steel," Materials Testing, vol. 62, no. 10, pp. 1041-1047, 2020.

[12] M. Naderi, M. Ketabchi, M. Abbasi, and W. Bleck, "Analysis of microstructure and mechanical properties of different high strength carbon steels after hot stamping," Journal of Materials Processing Technology, vol. 211, no. 6, pp. 1117-1125, 2011.

[13] F. Kara, M. Karabatak, M. Ayyıldız, and E. Nas, "Effect of machinability, microstructure and hardness of deep cryogenic treatment in hard turning of AISI D2 steel with ceramic cutting," Journal of Materials Research and Technology, vol. 9, no. 1, pp. 969-983, 2020.

[14] F. Kara, A. Çiçek, and H. Demir, "Multiple regression and ANN models for surface quality of cryogenically-treated AISI 52100 bearing steel," Journal of the Balkan Tribological Association, vol. 19, no. 4, pp. 570-584, 2013.

[15] B. Alexander, P. S. Christopher, W. Sooky, A. W. Mary, and M. J. Worswick, "Effect of cooling rate on the high strain rate properties of boron steel," International Journal of Impact Engineering, vol. 37, pp. 694-702, 2010.

[16] M. Nikravesh, M. Naderi, and G. H. Akbari, "Influence of hot plastic deformation and cooling rate on martensite and bainite start temperatures in 22MnB5 steel," Materials Science and Engineering: A, vol. 540, pp. 24-29, 2012.

[17] E. Nas and H. Gökkaya, "Experimental and statistical study on machinability of the composite materials with metal matrix Al/B4c/graphite," Metallurgical and Materials Transactions A, vol. 48, no. 10, pp. 5059-5067, 2017.

[18] K. N. Ashok, K. Yalcin, S. Eckehard, and B. Albrecht, "Sensitivity of material properties on distortion and residual stresses during metal quenching processes," Journal of $\mathrm{Ma}$ terials Processing Technology, vol. 210, pp. 204-211, 2010.

[19] R. George, A. Bardelcik, and M. J. Worswick, "Hot forming of boron steels using heated and cooled tooling for tailored properties," Journal of Materials Processing Technology, vol. 212, no. 11, pp. 2386-2399, 2012.

[20] L. He, G. Q. Zhao, and H. P. Li, "Optimization of quenching parameters for hot stamping boron steel B1500HS based on response surface methodology," Journal of Mechanical Engineering, vol. 47, no. 8, pp. 77-82, 2011.

[21] J. Zhou, Z. Y. Huang, L. Lei, and S. Y. Li, "Effect of quenching parameters on mechanical property of ultra high strength steel br1500hs based on response surface methodology," Journal of Harbin Institute of Technology (New Series), vol. 2, pp. 103-112, 2014.
[22] B. Öztürk and F. Kara, "Calculation and estimation of surface roughness and energy consumption in milling of 6061 alloy," Advances in Materials Science and Engineering, vol. 2020, Article ID 5687951, 12 pages, 2020.

[23] F. Bayraktar and F. Kara, "Investigation of the effect on surface roughness of cryogenic process applied to cutting tool," International Journal of Analytical, Experimental and Finite Element Analysis, vol. 7, no. 2, pp. 19-27, 2020. 